\title{
Investment and Construction Projects Management by Monitoring the Ecological State of Urban Space
}

\author{
Alexandr Orlov*, and Irina Chubarkina \\ Moscow State University of Civil Engineering, Yaroslavskoe shosse, 26, Moscow, 129337, Russia
}

\begin{abstract}
The authors carried out the analysis of the current state of the Russian investment and construction market, theory and practice of project analysis, which made it possible to determine the specifics of housing construction projects development during the crisis and highly uncertain external and internal factors of its implementation. Urban agglomerations development is a continuous process of transformation of the existing urban environment, where daily living activities are carried out, connected with changing social requirements. It includes various components of the integrated organization of the city's space: ecological, functional, architectural and artistic, socio-cultural aspects, as well as the organization of population activities. At the same time, taking into account the peculiarities of the city as a whole, urban development, in particular, is today the dominant task in urban planning practice. The mechanism of indicative risk assessment was used to develop the author's matrix for the processing of specific project risks during the crisis. Values of factor risk premiums are based on it, and they are taken into account when calculating the project efficiency. The use of this methodology makes it possible to identify and assess project risks with minimum resources, correct the parameters of the project's commercial efficiency and, taking into account the results obtained, draw a conclusion about the feasibility of further project implementation. One should choose a certain classification of environmental risks focusing on the goals and objectives of projects. This allows choosing the right methodology for assessing environmental risks at the stage of information collection and analysis, which in the future will make it possible to make the most complete and balanced decision. The use of the proposed recommendations makes it possible to take into account the impact of commercial, financial, legal, production and management risks during the crisis and, as a result, more accurately calculate the commercial efficiency of a development project.
\end{abstract}

\section{Introduction}

Most development projects in the construction industry are related to the housing construction sector and are currently implemented in conditions of economic instability.

\footnotetext{
* Corresponding author: alor333@gmail.com
} 
In the current conditions of the Russian economy an important role is played by experts' awareness of the current state of the construction market and the experience in overcoming economic crises of past years. Comparison by experts and comparable risk assessment of development projects of previous years, as well as possible emergence of new risks will provide a complete picture of possible unfavorable results during the implementation of an investment and construction project in the sector of housing construction $[2,8]$.

Studies aimed at assessing the effectiveness of the development project under consideration are necessary to determine the expected level of its profitability [15]. Today an investment or development (if we talk about real estate investments) project means a set of documents consisting of a business plan, a feasibility study of the project, the financial model of the organization, and the concept of project implementation [13, 19].

Among the main problems that city planners face in the course of modern cities development there are a number of basic, so to speak, general ones, reflecting the current state of large settlements and having a direct impact on the population $[1,3,21]$ :

- Lack of free land for building.

It seems that this problem can be solved in one of the following traditional ways: by expanding development in breadth or developing the city upwards. But this leads to other problems.

- The expansion of the city in breadth leads to transport problems.

- An increase in urban development upwards leads to a sharp increase in the population, but the parameters of the road network, infrastructure and the system of social facilities remain the same. This leads to a deterioration in the quality of life of people.

Based on the experience in the ecological reconstruction of urban areas in different regions, point solutions to this issue (for example, reclamation of a park zone or creation of a new comfortable residential eco-microdistrict) are temporary and economically inexpedient measures [17]. Since ecological reconstruction is a complex comprehensive measure, it seems necessary to develop special methods and methods for managing investment and construction projects at the municipal level that will take into account their specific features.

\section{Materials and Methods}

The methodological basis of this study is presented by methods of scientific analysis and synthesis, grouping, comparison and generalization, as well as by the method of indicative risks. Methods of factor analysis and statistical processing of information were used for the research.

The basis for the development of a regulatory, technical, organizational and legal framework in the field of ensuring the rational use of land for reconstruction should be environmental monitoring of the territory and analysis of the data obtained.

Each of the existing cities has its own individual appearance, despite the fact that each era gave rise to its own urban planning principles [4]. The planning structure and spatial organization of historical cities development reflects a diverse natural situation, landscape features, socio-economic and historical conditions of their development [20].

The architectural and construction development of European cities in recent decades, along with new construction, has been based on improving the living conditions of the population in a highly urbanized urban environment through the modernization and reconstruction of existing residential buildings with the improvement of its urban planning, architectural and structural solutions, with partial redevelopment of the built-up environment and buildings, improvement of operational qualities of structures and engineering equipment, improvement and development of buildings and institutions of the infrastructure with its partial reorientation, improvement of the transport and road network, 
improvement of amenities and landscaping, introduction of environmental measures [9, 12, 16]. At the same time works on the protection and restoration of architectural, historical and cultural monuments located in these cities are underway. Planning of the listed activities designated in the Russian literature by the terms "renovation" or "modernization" and "reconstruction", and in the foreign literature - "sanation" or "sanitation" (which means recovery), pursues the same goals of rehabilitation of the existing urban environment $[4,7]$.

Special pre-design studies are the basis for the formation of the concept of renovation of the residential development and buildings leading to a harmonious solution of social, economic, aesthetic, technical and environmenta.

1 problems while respecting the historical environment of urban development.

It is advisable to apply the following approach to the research, which can be represented by the following generalized block diagram presented in Figure 1.

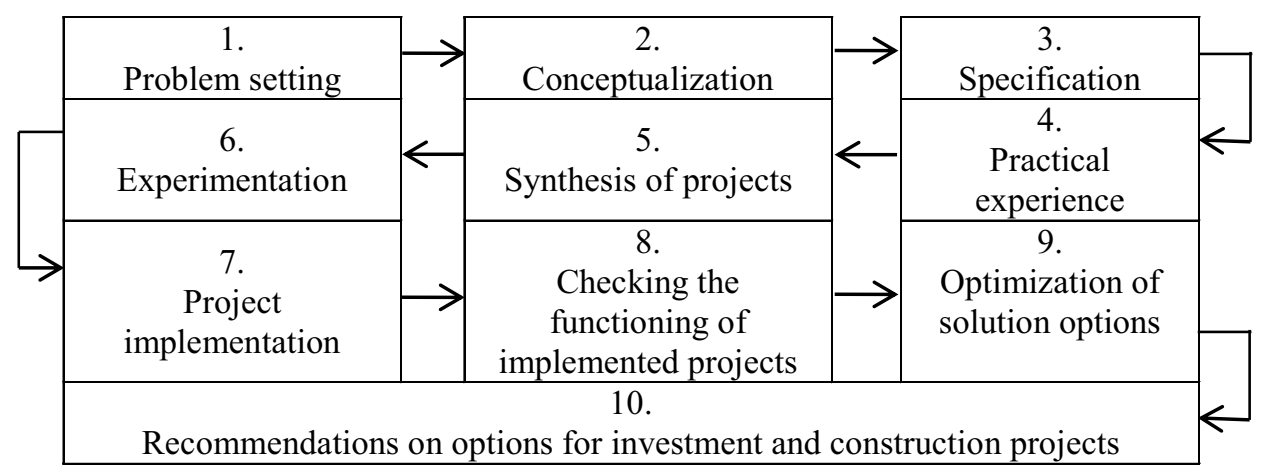

Fig. 1. Block diagram of urban agglomeration development projects

Today, in the process of urban development, it is necessary not only to develop new design solutions, but also to deal with various issues of territory complex development related to the coordination, solution, approval and explanation [5].

Figure 2 shows factors that have an impact on residential development.

These factors can be represented in two levels. First level factors are the fundamental factors that characterize an investment and construction project in terms of such factors as comfortability, degree of reliability and durability, environmental friendliness and hygiene, safety and cost-effectiveness. Each of them is subdivided into second-level factors that characterize the specifics of the state of the real estate object under consideration.

It is obvious that the environmental component in the development of urban agglomerations, regardless of the choice of a particular system of factors for the assessment of urban development, should be highlighted separately as a fundamental parameter of assessment [18]. 


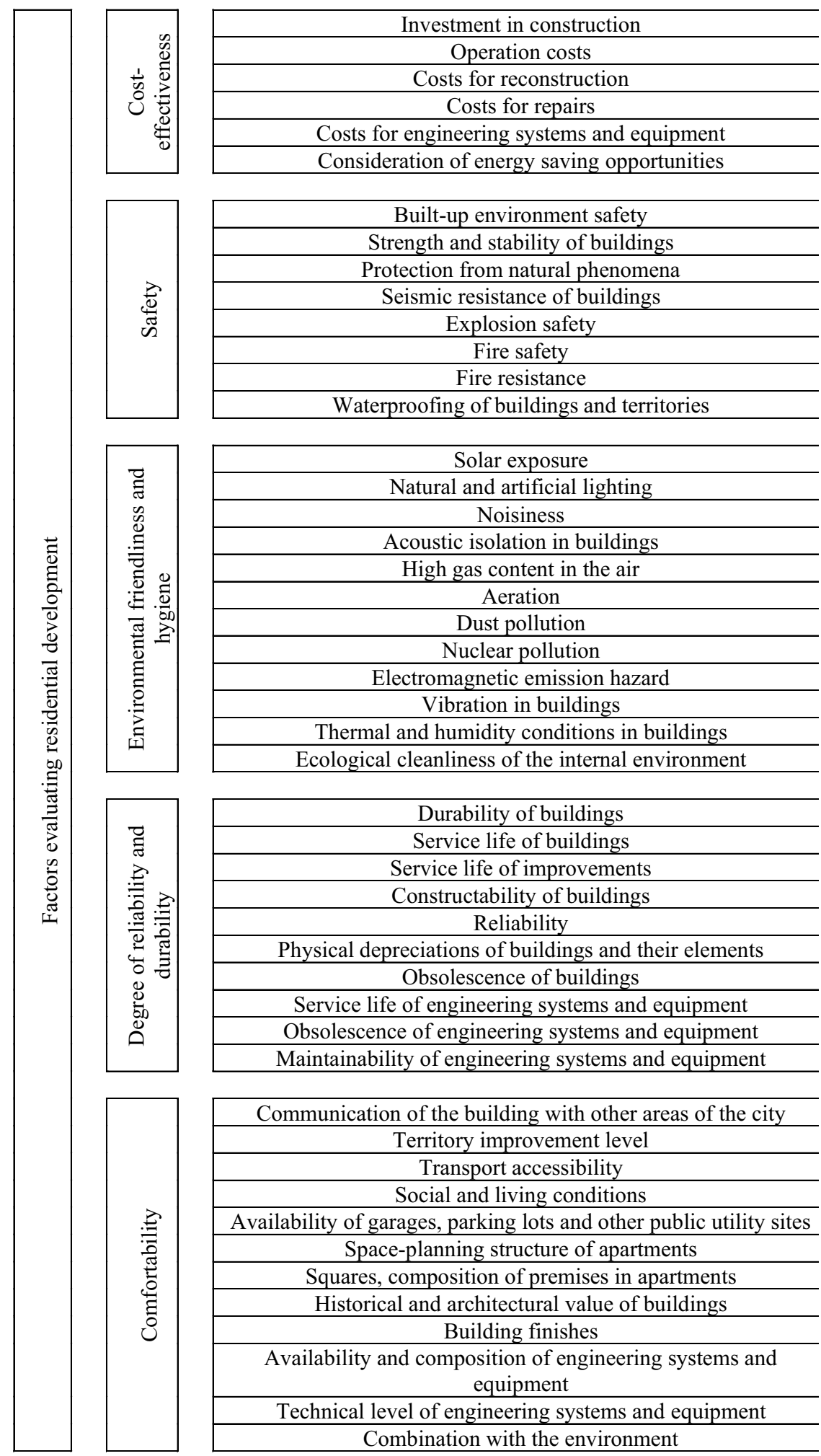

Fig. 2. Factors evaluating residential development 
The problem of taking into account risk factors for the economic assessment of development projects is widely discussed in practical and scientific methodological literature. However, special attention should be paid to the impact of specific risks arising during the economic crisis of the Russian economy and the construction industry in particular, on the performance indicators of the project [10]. Problems of risk assessment in the management of development projects are considered in works of Asaul A.N., Artamonov A.A., Vorontsova G.V., Grabovoi P.G., Ozerov E.S., Popelnyukhova S.N., Sevostyanov A.V., etc. A comprehensive and systematic presentation of the theory and methodology of risk assessment, which laid the foundations for the subsequent development of applied developments, is reflected in the studies of Nobel Prize winners in economics K. Arrow, J. Debreu, M. Friedman, J. Hicks, etc. However, despite the significant amount of materials, research, scientific articles and other literature, the existing methods of quantitative and qualitative risk analysis have a number of significant shortcomings in the implementation of housing projects during the crisis.

\section{Results}

Integrated development of residential buildings in cities can be presented in the form of interrelated indicators reflected in Figure 3.

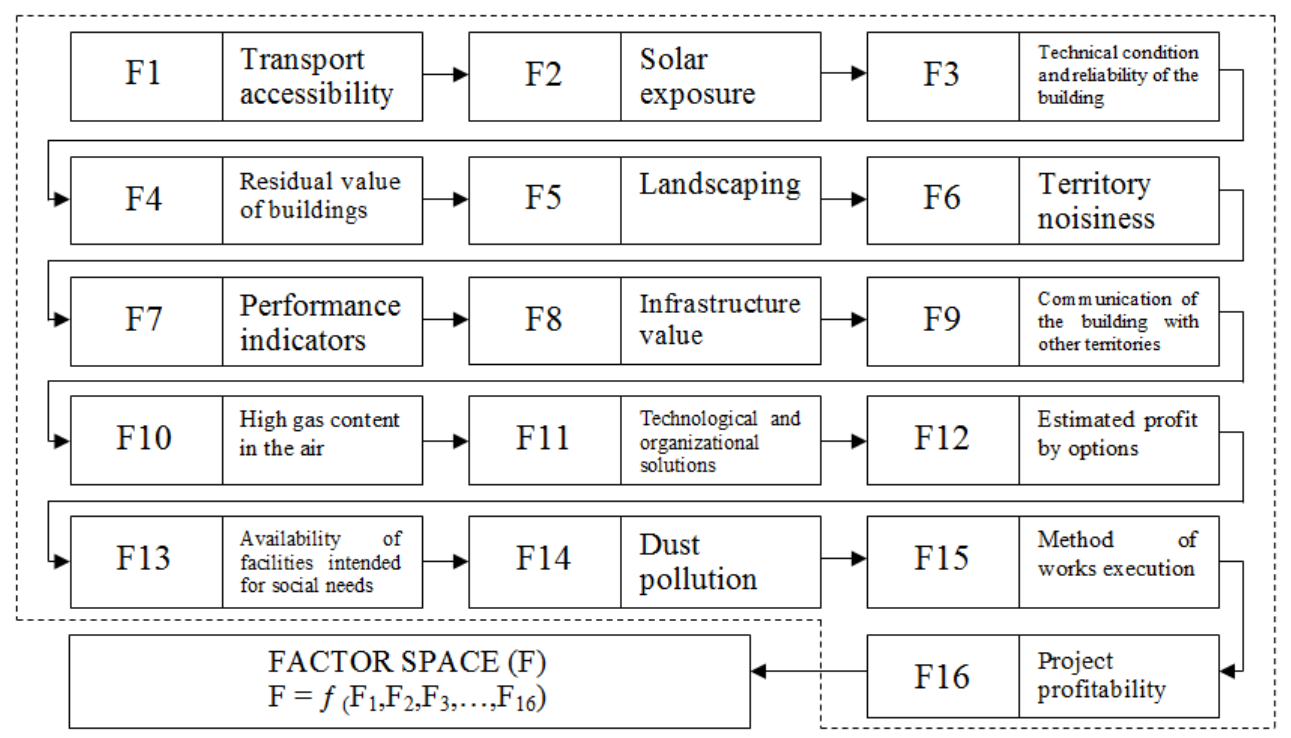

Fig. 3. Factor space influencing residential development

In this factor space the following main criteria can be distinguished:

- Technical and physical (engineering and construction, architectural).

- Industrial (economic).

- Environmental.

- Transport.

- Political.

- Economic.

- Public (the opinion of the authorities, the population).

Factors F1, F5, F9, F13 are associated with such urban planning indicators as transport accessibility, landscaping, connection of the development with other city areas, availability of facilities intended for social needs, etc. 
Factors assessing the ecological and sanitary-hygienic state of urban development are taken into account as factors F2, F6, F10, F14: solar exposure, noisiness of the territory, gas content in the air, dust pollution, electromagnetic emission hazard, nuclear pollution, aeration regime.

Factors F3, F7, F11, F15 are associated with the choice of the method of works execution depending on the technical condition of buildings: the technical condition and reliability of the building, structural, technical and organizational solutions.

Factors characterizing residential development in terms of economic indicators are designated as factors F4, F8, F12, F16: residual value of buildings, residual value of infrastructure, profit assessment by options, profitability of the project and an assessment of the volume of capital investments.

Let us consider the environmental aspects of the research in detail.

It is customary to assess the ecological state of the environment in urban planning using two aspects. In the first case the issue of air pollution by various impurities associated with the environment of the building is considered, and in the second - vibration, electromagnetic and other negative phenomena are assessed $[6,11]$. To track the ecological state of the environment in Russia, an ecological monitoring system has been introduced, which is currently the main tool for collecting and analyzing information on the ecological state of the urban area.

Note that the definition of environmental risks is based on risk analysis. It is not enough just to realize or even approximately calculate the environmental risk. It is required to understand the reason for the risk.

It is advisable to start justification of schemes for the integrated greening of urban areas and organization of territorial zones with closed economic ties with the study of:

- The demographic situation.

- The amount of industrial and household waste.

- The number of vehicles per person.

- The provision of residential areas with health care, social and service enterprises and institutions.

- The availability of industries, resources used by these industries, the degree of environmental hazard of industries [14].

Goals of future project are determined at the stage of justification:

- Obtaining of the maximum practical results related to reasonable greening of the territory.

- Rational (selective) use of natural resources.

- Improving the quality of life through the successful implementation of social and recreational activities and the simultaneous solution of environmental and economic problems.

At the current stage of development of the economic and political situation in the Russian economy, there is no universal method that allows taking into account various risk factors when calculating the expected efficiency of a housing construction project.

Environmental risks can be voluntary and imposed when it relates to the society's attitude to possible negative impacts on the environment, and hence the population.

So, the following classification of environmental risks can be shown in Figure 4. 


$$
\begin{aligned}
& \text { Natural and ecological risks } \longrightarrow \begin{array}{l}
\text { Risks caused by changes in the natural } \\
\text { environment }
\end{array} \\
& \text { Technical and environmental } \\
& \text { risks } \\
& \text { Risks associated with the emergence and } \\
& \text { development of the technosphere }
\end{aligned}
$$

Fig. 4. Environmental risks

According to the method of indicative risk assessment, values of factor risk premiums are calculated on the basis of the matrix developed by the author, in which all the risks of the project

- are vertically distributed into 6 groups (factors):

- Production risks (I)

- Financial and economic risks, including project low liquidity risks (II)

- Management risks, including project development risks (III)

- Legal risks (IV)

- are horizontally subdivided in the following way:

- By the level of occurrence - external (a) and internal (b).

- By the degree of control - controlled $(\gamma)$ and uncontrolled $(\delta)$.

So, the calculation of risks can be presented in the form of a matrix:

$$
R s=\left\{\begin{array}{cccc}
I_{a \gamma} & I_{a \delta} & I_{b \gamma} & I_{b \delta} \\
I I_{a \gamma} & I I_{a \delta} & I I_{b \gamma} & I I_{b \delta} \\
I I I_{a \gamma} & I I I_{a \delta} & I I I_{b \gamma} & I I I_{b \delta} \\
I V_{a \gamma} & I V_{a \delta} & I V_{b \gamma} & I V_{b \delta}
\end{array}\right\}
$$

Each risk on the expert assessment sheet is assigned a group number (I-IV). Based on expert assessments of the average probability of risk occurrence, the indicator of each risk is determined in accordance with the Harrington verbal and numerical scale presented in Figure 5. Values of each element of the matrix (indicator Ia $\gamma, \mathrm{I} a \delta, \ldots, \mathrm{IVb} \delta$ ) are calculated as the arithmetic mean of the corresponding indicators. 


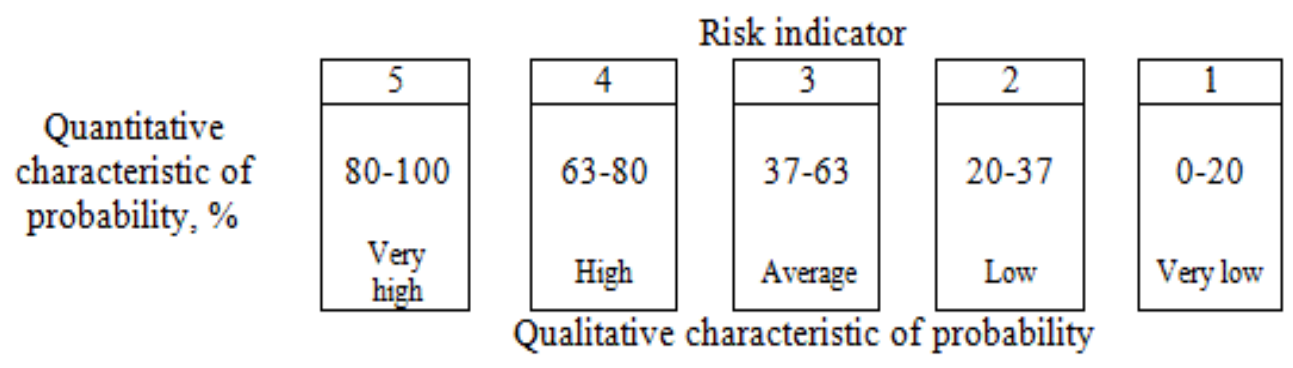

Fig. 5. Harrington verbal and numerical scale

The value of the risk premium (Pr) for each factor (I-IV) is determined as the arithmetic mean of the indicators in horizontal direction. The discount rate is determined by adding the risk-free rate of return (Rf) and all factor risk premiums.

$$
W A C C=R f+\sum(\operatorname{Pr}(I)+\operatorname{Pr}(I I)+\operatorname{Pr}(I I I)+\operatorname{Pr}(I V))
$$

So, the obtained value of the discount rate is used to correct the calculated indicators of the commercial efficiency of a development project at the stage of business planning; and conclusions are drawn about the feasibility of further implementation of the project.

\section{Conclusion}

As noted above, before carrying out measures for eco-reconstruction it is necessary to conduct studies, on the basis of which the most correct and reasonable decision is chosen. Such studies should be carried out in different directions with the choice of the most progressive and modern solutions.

Today, the most significant and relevant measures for the reconstruction of urban development are as follows:

- Freeing of inefficiently used territories.

- Neutralization and processing of solid household waste.

- Solving transport problems through the development of underground and aboveground space.

- Greening of urban areas.

The environment, in which physical conditions of living are formed, the convenience of living, including functional and technical comfort, as well as aesthetic functions of the environment are the main assessments of the city from the standpoint of its perception by a person in terms of recognizing it as comfortable for life. In this regard in the course of ecological development of urban areas it is necessary, first of all, to take into account the needs of people living in the built-up area.

\section{References}

1. B. Majerska-Palubicka, Advances in Intelligent Systems and Computing, 788, 118-127 (2019)

2. D. Radogna, M. Romano, Advances in Intelligent Systems and Computing, 788, 226235 (2019)

3. E. Frolova, M. Vinichenko, A. Kirillov, O. Rogach, E. Kabanova, International Journal of Environmental and Science Education, 11(15), 7421-7430 (2016) 
4. E. Gusakova, IOP Conference Series: Materials Science and Engineering, 463(2), 022042 (2018)

5. E. Shcherbina, E. Gorbenkova, IOP Conference Series: Materials Science and Engineering, 365(2), 022039 (2018)

6. H. Osman, H. Structure and Infrastructure Engineering, 12 (1), 108-121 (2016)

7. K. Yung, N. Nafar, International Review of Economics and Finance, 48, 423-439 (2017)

8. Larionov, E. Nezhnikova, International Journal of Applied Engineering Research, 6, 4433-4439 (2016)

9. M. Biłozor, A. Biłozor, R. Wisniewski, Land Use Policy, 61, 511-525 (2017)

10. N. Safronova, E. Nezhnikova, A. Kolhidov, MATEC Web of Conferences, 106, 08024 (2017)

11. Nezhnikova E and Kankhva V 2017 Izvestiya Vysshikh Uchebnykh Zavedenii, Seriya Teknologiya Tekstil'noi Promyshlennosti. 2(368)

12. P.H. Brown, How Real Estate Developers Think: Design, Profits, and Community (University of Pennsylvania Press, 2015)

13. Papelniuk O 2017 MATEC Web of Conferences. 10608044

14. S. Prestamburgo, F. Sgroi, C. Zanin, Science of the Total Environment, 663, 944-949 (2019)

15. Sun Zi Bingfa, C. H. Wee, Source of the Document Global Business and Organizational Excellence, 36 (2), 34-45 (2017)

16. V. Kankhva, IOP Conf. Series: Earth and Environmental Science, 90, 012175 (2017)

17. V. Kankhva, Procedia Engineering, 165, 1300-1304 (2016)

18. W. Januszewski, Advances in Intelligent Systems and Computing, 788, 79-89 (2019)

19. W.K. Hughen, D.C. Read, Land Use Policy, 61, 1-11 (2017)

20. Y. Kog, Practice Periodical on Structural Design and Construction (2018)

21. H. Donner, H.-S. Song, M. Wilhelmsson, Journal of Housing Economics, 34, 60-68 (2016) 